\title{
ARTICLE \\ Understanding Antecedents of Civic Engagement in the Age of Social Media: From the Perspective of Efficacy Beliefs
}

\author{
Siyoung Chung ${ }^{1}$ KyuJin Shim ${ }^{2 *}$ \\ 1. Independent researcher \\ 2. University of Melbourne, Australia
}

\section{ARTICLE INFO}

Article history

Received: 27 April 2020

Accepted: 6 July 2020

Published Online: 30 July 2020

Keywords:

Political self-efficacy

Political collective efficacy

Knowledge sharing efficacy

Social media use

Civic engagement

\begin{abstract}
This study examines three efficacy beliefs-political self-efficacy, political collective efficacy, and knowledge sharing efficacy-as antecedents of social media use and civic engagement. Employing more than one thousand samples in Singapore, we empirically test (a) a conceptual framework that can provide an understanding of the relationship between the three types of efficacy and civic engagement and (b) the underlying mechanism through which the three types of efficacy beliefs affect civic engagement via social media. The findings suggest that knowledge sharing efficacy was found to play an important role in mediating the relationships between social media use and political self-efficacy, political collective efficacy, respectively, which, in turn, influences the social media use.
\end{abstract}

Fowler's blog post" ${ }^{[3]}$.

Asian countries such as China and India are no exception as for the impact of social media use on civic engagement and participation. Despite social pressure and censorship inhibiting freedom of expression, it appears that social media use could change Chinese society as the online media facilitates loosely structured networks and subsequently increases civic engagement. For example, Starbucks closed its store at the Forbidden City in China due to overwhelming criticism from power bloggers and online users who perceived Starbucks' business in the Forbidden City disrespectful for China's historical and cultural heritage ${ }^{[4]}$ India has also seen the power of social media in providing marginalized stakeholders with global attention and support and connections with international

*Corresponding Author:

KyuJin Shim,

University of Melbourne, Australia;

Email:Kyujin.shim@unimelb.edu.au 
NGO (non-governmental organization)s. A YouTube video of a rap song which criticized the dealing of mercury poisoning by Hindustan Unilever instantly drew the attention from a global community and generated enormous support for the victims of mercury poisoning and activists. ${ }^{[5]}$ As such, research in civic engagement has paid attention to the role of social media in civic engagement and reported a positive association between social media use and civic engagement ${ }^{[6]}$.

Despite a number of studies that examined the relationship between the social media use and civic engagement, little is known as to how citizens' use of social media such as Facebook and Twitter works as motivators for civic engagement, and more importantly, what antecedents exist to people's social media use. Based on previous research on efficacy, media use and civic participation, ${ }^{[7,8]}$ we pay particular attention to the roles of efficacy in social media use and civic engagement.

Efficacy has appeared in political participation research for decades. ${ }^{[9,10]}$ As Bandura (1997) posited that the efficacy concept needs to reflect the specificity of the task and the context, ${ }^{[1]]}$ we would like to investigate the effects and roles of three types of efficacy about civic engagement, namely political self-efficacy, political collective efficacy, and knowledge sharing efficacy.

Political self-efficacy is defined as "the feeling that political and social change is possible, and that the individual citizen can play a part in bringing about this change". ${ }^{[12]}$ Political collective efficacy is a group-level concept that can be achieved only through interactive and collaborative group processes. Evidence about the effects of political self- and collective efficacy has accumulated in the literature on political and civic engagement. However, these two efficacy beliefs are not enough in explaining the recent trend of civic engagement that is characterized by its excessive use of social media.

Many civic and social movements such as Occupy Wall Street (2011) and Ice Bucket Challenge (2014) are known for their strategic use of social media. ${ }^{[13,14]}$ The nature of social media makes all social media communication as a public good directs our attention to another efficacy belief, knowledge sharing efficacy, ${ }^{[15]}$ which is defined as the selfassessment of one's confidence that his or her knowledge can improve the collective processes. ${ }^{[15,16]}$ Without such confidence, one may not overcome the fear of being criticized, losing face, or creating a negative impression when sharing and expressing opinions on social media. Surprisingly, little research has been conducted so far as to the role and the effects of knowledge sharing efficacy in motivating civic engagement.

To address the gaps mentioned above, we draw on the concepts of three efficacy beliefs -political self-efficacy, political collective efficacy, and knowledge sharing efficacy-and propose a research model with which we empirically tested the relationship between social media use and civic engagement. Specifically, our objectives of this study are: (a) to develop a conceptual framework that can provide a better understanding of the relationship between the three types of efficacy and civic engagement; (b) to delineate the underlying mechanism through which social media use is connected with the efficacy beliefs and civic engagement; (c) to empirically examine the degree to which the three efficacy beliefs have an impact on civic engagement. Therefore, this study aims to contribute to the body of knowledge to the research area of social media use and civic engagement by explicating the dynamics of three types of efficacy, social media use, and civic engagement.

\section{Literature Review}

In this study, civic engagement is defined as based on the concept of political consumerism suggested by previous work. ${ }^{[17]}$ This study examines the communicative aspects of political consumerism in light of the theoretical framework of civic engagement as an extension of traditional political participation.

As such, this study looks at civic engagement activities encompassing individual and collective, and various forms of voluntary activities to resolve social problems that might affect communities and a broad society, especially in the digital context.

It can include an individual's donation to and participation in the charitable activities for non-profit or non-government organizations, participating in the discussion about politics or social issues on social media, signing an online petition about a local, national, or international issue, and boycotting or purchasing certain products or services for political/ethical/environmental reasons.

However, we excluded explicit forms of political behavior such as volunteering to help a political party or a politician, or donation to a politician or a political party, attending political rallies, meeting politicians, expressing supports for politicians on social media, and writing to the government or a member of parliament.

\subsection{Social Media and Civic Engagement}

The advent of social media has transformed significantly the way civic engagement occurs ${ }^{[18,19,20]}$. Digital media technology has facilitated and streamlined civic and political engagement through prompt and convenient 
content creation and distribution online. ${ }^{[6,21]}$ Even though the relationship between social media use and civic engagement still needs to be further investigated,${ }^{[17,22,23,24,]}$ extant research has so far indicated a strong association between social media use and civic participation. People who engage in civic activities are identified as frequent social media users. ${ }^{[25,26]}$ Further, digital media use has effect on political consumerism, ${ }^{[6]}$ political participation, ${ }^{[27]}$ youth protest, ${ }^{[26]}$ and youth collective activism, ${ }^{[28]}$ although the relationship between these varies ${ }^{[29]}$.

Some of the possible explanations about the relationship between social media use and civic may be found in several previous research. Kim, Hsu, and Gil de Zúñiga's (2013) suggested due to the nature of social media which allows easy access to information, anonymous participation, and sharing of information with others, even people who are shy and less open to participation or who feel their ability is limited, can consider social media as their channel for civic participation. ${ }^{[30]}$ Gil de Zúñiga et al. (2012)'s study indicates that "seeking information via social network sites predict people's civic engagement and political participatory behavior that encompasses both online and offline activities". ${ }^{[31]}$ Shirky (2008) emphasized that "social media technologies contributed to the ease and speed with which a group can be mobilized" (p. 12). ${ }^{[32]}$

Based on the above literature review, we presume that social media use will be related to civic engagement behavior. Our research delimits the scope of civic engagement to apolitical, voluntary activities to resolve social problems that might affect communities and broad society.

H1: Social media use is positively associated with their civic engagement behavior.

\subsection{Political Self-efficacy and Political Collective Efficacy}

Among various factors that influence civic engagement, efficacy has been identified as a key determinant. Bandura (1997) defined self-efficacy as one's strong belief that one can exert substantial controls over events in one's life and proposed that self-efficacy is a motivator to exert an effort, endure hardship, welcome challenge, and strive for success. ${ }^{[1]]}$ Cumulative research has discerned an accumulated significant effect of perceived self-efficacy on individuals' decision-making processes and outcomes in various settings including education, society, politics, and organizations. ${ }^{[33,34]}$ Self-efficacy is a task- and situation-specific concept because people evaluate their level of self-efficacy about specific goals or contexts. Since then, a variety of self-efficacy judgments has been proposed and measured for different tasks or in different settings.

In the area of civic engagement, political self-efficacy (PSE) has been proposed as a task specific efficacy concept. PSE is defined as "the feeling that political and social change is possible, and that the individual citizen can play a part in bringing about this change". ${ }^{[12]}$ Empirical research has consistently linked PSE with political participation such as voting, writing letters and petitions for a political group, and donating to political parties or politicians. ${ }^{[12,35,36]}$ Recent studies have tested the role of PSE in the context of civic engagement. Delli-Carpini (2000) suggested that PSE is the motivation for civic participation. ${ }^{[37]}$ Hoffman and Thompson (2009) and Hope (2016) both found a moderating effect of PSE on civic participation. ${ }^{[38,39]}$ Kahne and Westheimer (2006) found that participation in the community-based project increased PSE among Black youth. ${ }^{[40]}$ Therefore, we posit that PSE has a positive relationship with civic engagement.

H2: PSE has a positive relationship with civic engagement.

While political efficacy is limited to the exercise of the individual agency, collective efficacy is a group-level concept that can be achieved only through interactive and collaborative group processes. ${ }^{[1]}$ Cumulative literature has found the positive relationships between the perceived collective efficacy and the groups' motivational investment in their undertakings, their staying power in the face of impediments and setbacks, and their performance accomplishments ${ }^{[41,42]}$

Collective efficacy is particularly important in the context of civic engagement because civic engagement in its very core is collective behavior. Virtually all social issues such as neighborhood crime, public disorder, and poverty need to amass the aggregated efforts from the public to bring about changes at a broader level. In this regard, Yeich and Levine (1994) proposed political collective efficacy (PCE) as a component of the political efficacy construct. ${ }^{[33]}$ This component represents perceptions of systematic responsiveness to collective demands for change. While PSE represents perceptions of the responsiveness of the political system to the actions of individuals, PCE represents perceptions of system responsiveness to those of the masses. Past studies have found a positive effect of PCE on various civic activities. For example, PCE was negatively associated with both homicide rates and non-lethal partner violence. ${ }^{[44]}$ Along with social capital, PCE was also found as a significant predictor of lowering mortality rates in both men and women across sub-regions of Hungary. ${ }^{[45]}$ In the same vein, Burdette, Wadden, and Whitaker (2006) studied the 
link between health and collective efficacy, reporting that obesity was more prevalent in neighborhoods with lower levels of collective efficacy. ${ }^{[46]}$ Therefore, we posit that PCE has a positive relationship with civic engagement.

H3: PCE has a positive relationship with civic engagement.

Since Bandura (1997) asserted that self-efficacy and collective efficacy are correlated, we hypothesized as follows. ${ }^{[1]}$

H4: PSE and PCE have a positive association.

\subsection{Efficacy Beliefs and Social Media Use}

Efficacy and goals are highly related. Highly efficacious people are motivated to perform well and try to organize and coordinate efforts and resources to achieve their goals. ${ }^{[47]}$ Social media is an excellent tool for these people by providing them with information, knowledge, networks, and other resources that may not be locally available. For example, people follow Facebook pages of organizations that they like and join Facebook groups to share their interests and views about a common cause and issue and organize activities and events to make changes or create impacts. According to a recent study, the average number of pages, groups, and events a user is connected to is 80 (Aslam, 2018). ${ }^{[48]}$ Twitter has also active online dialogues and campaigns about social issues and problems. Hashtags are widely used to create discussion threads for an issue or to support a movement on Twitter (e.g., \#MeToo, \#BlackLivesMatter, \#IceBucketChallenge, etc.).

Past studies examined the relationship between PSE and social media use. ${ }^{[49]}$ Use of social networking sites for political purposes could have a positive impact on political learning efficacy and, thus, on knowledge and participation. ${ }^{[50]}$ Unlike PSE, however, little research has been conducted to examine the relationship between media use and PCE. Given the similarity in belief foundation of PSE and PCE, a positive relationship between social media use and PCE is expected.

H5: There is a positive relationship between PSE and social media use.

H6: There is a positive relationship between PCE and social media use.

\subsection{Knowledge Sharing Efficacy}

While literature in civic engagement has widely accepted PSE and PCE as key determinants, these two efficacy beliefs alone are not sufficient to explain civic engagement. The nature of social media platforms makes all communication public, making the individual subject to judgment and criticism of the audience. To withstand the negative responses and scrutiny of other participants on social media, one must be confident about the knowledge and information that he or she shares with others. This type of confidence is different from PSE and PCE and is more pertaining to the value and utility of one's knowledge of the goals. This type of confidence is called knowledge sharing efficacy (KSE) which is defined as the self-assessment of one's confidence that his or her knowledge can improve the collective processes. ${ }^{[15,16]}$ KSE has been tested in the context of management and education and found significant in its effect on knowledge sharing intention. ${ }^{[1,52]}$ Cho, Chen, and Chung (2010) also found a positive effect of KSE on the information sharing intention among Wikipedia contributors. ${ }^{[53]}$

$\mathrm{KSE}$ is expected to play a more critical role in social media environment. As mentioned earlier, information or opinions shared on social media become a public good which is met with the public scrutiny and potential criticism. ${ }^{[15]}$ An individual who decides whether or not to share information or opinion on social media considers costs and benefits associated with this sharing behavior. The cost includes a fear of misleading others with wrong or outdated information, a fear of being evaluated negatively by others, a fear of creating negative impressions on others, a fear of losing face. ${ }^{[4,55]}$ Ardichvil, Page, and Wentling (2006) stated that "people are afraid that what they post may not be important (may not deserve to be posted), or may not be completely accurate, or may not be relevant to a specific discussion" (p. 70). ${ }^{[54]}$ These fears will discourage the desire to share information and opinion with others.

A high level of perceived benefits of sharing information can help overcome these fears and increase online sharing behavior. If an individual favorably assesses the value and utility of the contribution of one's knowledge to a collective action, the person is likely to participate in sharing behavior on social media. The person with high KSE foresees the goodness that his/ her information sharing brings to the causes, overcomes the psychological barriers, and engages in active sharing information, knowledge, and resources on social media. Hence, we hypothesized as follows.

H7: The paths between PSE and social media use and PCE and social media use are mediated by KSE.

KSE and the other efficacy beliefs can be related. Strongly motivated, a person with high PSE will actively seek, collect, and process information and eventually learn a great deal about the subject, which will boost the confidence in the values and utility of the information he/she shares. Unlike PSE, PCE is a judgment about 
the group, Figure 1 shows the research model and the hypotheses.

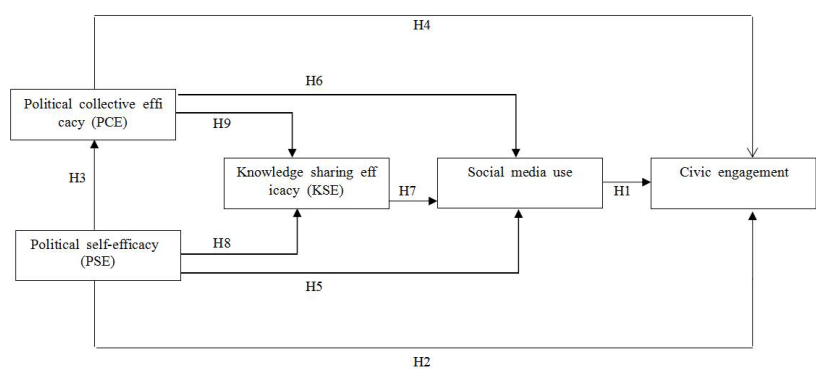

Figure 1. Theorized Research Model and Hypotheses

Notes:

H1: Social media use is positively associated with their civic engagement behavior.

H2: PSE has a positive relationship with civic engagement.

H3: PSE and PCE have a positive association.

H4: PCE has a positive relationship with civic engagement.

H5: There is a positive relationship between PSE and social media use.

H6: There is a positive relationship between PCE and social media use.

H7: There is a positive relationship between KSE and social media use.

H8. There is a positive relationship between PSE and KSE.

H9. There is a positive relationship between PCE and KSE.

\section{Method}

\subsection{Procedure}

This study employed focus group interviews and an online survey. To identify unknown psychological attributes and behavioral patterns associated with media use (traditional and social) and the types of civic engagement people participate in, a total of six sessions of focus group interviews were conducted, each session comprising 10 participants. A \$20 voucher was given to each participant as an incentive.

To pre-test the reliability of the measures, we conducted a pilot test of the survey questionnaire using 50 online panels from a research company. Based on the results of the pilot test, we improved the wording and length of the survey. The results showed that the levels of reliability of the measures were adequate. The final survey was distributed by the research company to its online panels. The survey took about 10 to 20 minutes to complete. At the end of the survey, respondents were offered credit from the research company.

\subsection{Sample}

Of the 1587 respondents, $50.4 \%(n=800)$ were female and $49.6 \%(n=787)$ were male. This is almost the same as the statistics of the Singapore citizen in $2016^{[56]}$. The percentages of the age group 18-19, 20-29, 30-39, 40-49, $50-59$, and 60 or older are $3.6 \%, 22.7 \%, 26.5 \%, 22.4 \%$,
$16.4 \%$, and $7.4 \%$ respectively. Compared to the statistics, our sample is more in 20-29 (+4.13\%), 30-39 (+5.96\%), and $40-49(+0.88 \%)$ groups and fewer in 50-59 $(-4.78 \%)$ and 60 or older $(-7.28 \%)$ groups. Given the fact that the Internet use is saturated among the younger generations but not among the older generations (CNA, 2015), this distribution is acceptable. ${ }^{[57]}$

\subsection{Measures}

In total, 46 questions were developed; these covered the key variables (41) and the demographic information (4). Most of the survey items were adapted from prevalidated research work, so as to increase the construct validity, except the measure for social media use, which was created for this study. For all measures, 5-point Likert scales were used $(5=$ strongly agree, $3=$ neither agree nor disagree, $1=$ strongly disagree) except for social media use which was measured with frequency. The survey items for each scale are presented in Appendix 1; the intercorrelations among them are reported in Table 1.

Civic engagement. The scales of civic engagement were created by adding nine items measuring the frequency of respondents' civic engagement behavior $(\alpha=882)$. The measures cover online civic engagement behavior. These items (total 9) were borrowed from previous research on civic engagement and revised for the purpose of our research. ${ }^{[6,31]}$ Then, new five items of online civic engagement were created by authors to measure participating in an online discussion of social issues or sharing information related civic matters with others. (see Appendix for measures).

Political self-efficacy (PSE). This variable $(\alpha=.689)$ was measured using nine items (Niemi et al., 1991) such as "I consider myself to be well qualified to participate in politics" and "generally speaking, ${ }^{[36]}$ I feel that I have a pretty good understanding of the important political issues facing our country."

Political collective efficacy (PCE). This variable was measured with eleven items, borrowed from Yeich and Levine (1994). ${ }^{[43]}$ These include "Politicians would respond to the needs of citizens if enough people demanded change.", "We are definitely able to accomplish something positive since we are a competent group of people" and "As a people, we can cooperatively develop and carry out programs to benefit us all, even when difficulties arise." $(\alpha=$.920).

Political knowledge sharing efficacy (KSE). This study introduces five novel knowledge efficacy items intended to tap one's confidence that his or her knowledge can improve the collective processes. Three items were borrowed from Kalman et al. (2002), and Lin (2007) 
and two items were created. ${ }^{[15,16]}$ These are including "I am confident in my political knowledge that is valuable to others and "I have the expertise required to provide valuable knowledge for others" $(\alpha=.778)$.

Social media use. The use of social media was measured with two questions which ask the number of minutes a day people Facebook and Twitter for information related to social and civic matters. Respondents were given with the number of minutes in five-minute intervals (from 5 to 100). The scale was obtained by averaging the scores for Facebook and Twitter use. The internal reliability was at the adequate level $(\alpha=$. $600)$.

Table 1. Bicorrelations of summated items

\begin{tabular}{|c|c|c|c|c|c|}
\hline & PCE & PSE & KSE & SOCIAL MEDIA & CIVIC \\
\hline PCE & 1 & & & & \\
\hline PSE & $.301^{* *}$ & 1 & & & \\
\hline KSE & $.327^{* *}$ & $.556^{* *}$ & 1 & & \\
\hline SOCIALMEDIA & $.096^{* *}$ & $.125^{* *}$ & $.198^{* *}$ & 1 & \\
\hline CIVIC & $.213^{* *}$ & $.282^{* *}$ & $.384^{* *}$ & $.349^{* *}$ & 1 \\
\hline
\end{tabular}

Note:

**. Correlation is significant at the 0.01 level (2-tailed).

\section{Results}

To explore relationships among three types of efficacy beliefs, social media use, and civic engagement, we performed path analysis $(\mathrm{N}=1587)$. To test the hypotheses and the research model, structural equation modeling analyses were performed using a path analysis approach which is useful as it evaluates the global model fit and tests other competing models in comparison with the theorized model. All the factors in the model were composite variables. The data were analyzed with the AMOS 23 software program, with a covariance-based approach, using maximum-likelihood estimation.

\subsection{Hypotheses Testing}

Regarding the relationships observed among the endogenous variables, research results supported nine direct paths. The path between social media use and civic engagement was significant $(\beta=.196, \mathrm{p}<.001)$ and had a positive association with civic engagement. Hence, H1 is supported. PSE $(\beta=.179, \mathrm{p}<.001)$ and PCE $(\beta=$ $.099, \mathrm{p}<0.001$ ) were both positively associated with civic engagement, which supported $\mathrm{H} 2$ and $\mathrm{H} 4$. As predicted, PCE and PSE had a positive relationship ( $\beta=.301, p$ $<.001$ ), thus H3 was supported. As for the relationship with social media use, only KSE was found to have a significant relationship $(\beta=.178, \mathrm{p}<.001)$, which supported H7. PSE and PCE did not have a significant relationship with social media use. Therefore, H5 and H6 were not supported. In terms of relationships with KSE, both PSE $(\beta=.560, \mathrm{p}<.001)$ and PCE $(\beta=.174$, $\mathrm{p}<.001$ ) have a positive association, which provided support for $\mathrm{H} 8$ and $\mathrm{H} 9$. In terms of total effect on civic engagement, PSE had the most total effect $(\beta$ total $=.200$ $\mathrm{p}<.001)$, followed by Social media use $(\beta$ total $=.196, \mathrm{p}$ $<.001)$, and PCE $(\beta$ total $=.111, \mathrm{p}<.001)$, KSE $(\beta$ total $=$ $.035, \mathrm{p}<.001)$.

Overall, the results support our research model, in that the three efficacy beliefs had a positive relationship with one another. KSE has a positive association with social media use, which, in turn, had a positive relationship with civic engagement. PSE and PCE also had a direct positive association with civic engagement.

\subsection{Post-hoc Analysis and the Suggested Final Model}

The initial test of the theorized model did not fit the theoretical model well (See table 2). To identify the best fitting model, nonsignificant paths were removed via a modification procedure. Also, a path between PSE and civic engagement was added to enhance the model fit.

Table 2. Data-Model Fits for Comparing Theorized Model and Final Model $(\mathrm{n}=1587)$

\begin{tabular}{|c|c|c|c|c|c|c|c|c|c|c|}
\hline Model & $\boldsymbol{\chi} \mathbf{2}$ & $\mathbf{d f}$ & $\mathbf{p}$ & $\begin{array}{c}\boldsymbol{\chi} \mathbf{} \\
\text { df }\end{array}$ & $\mathbf{C F I}$ & $\mathbf{T L I}$ & $\mathbf{S R M R}$ & $\mathbf{R M S E A}$ & $\boldsymbol{\Delta} \boldsymbol{\chi} \mathbf{2}$ & $\boldsymbol{\Delta} \mathbf{d f}$ \\
\hline $\begin{array}{c}\text { Theorized } \\
\text { Modela }\end{array}$ & 66.492 & 1 & .000 & & .940 & .403 & .0399 & .234 & & \\
\hline $\begin{array}{c}\text { Final } \\
\text { Modelb }\end{array}$ & 22.861 & 2 & .352 & & .940 & .801 & .0091 & .117 & 43.631 & 1 \\
\hline
\end{tabular}

Notes:

a Theorized model is the model including all the nine paths hypothesized by theoretical assumptions.

bFinal model is the model without insignificant paths between PSE, PCE and social media use. Also, one path between KSE and civic engagement was included.

The final model is better fitting and more parsimonious than the originally theorized model without substantially changing the theorized relationships (see Figure 2). We assessed the model fit using multiple goodness-of-fit indexes. First, the chi-square statistics were insignificant $(\chi 2(2)=2.090, p=.352)$ which indicated that the fit of the data with the hypothesized model was adequate. Other model fit indexes such as CFI, TLI, SRMR, and RMSEA show an acceptable fit for our research model: $\mathrm{CFI}=.940$, $\mathrm{TLI}=.801$, SRMR $=.0093$, and RMSEA $=.117$. These goodness-of-fit indexes indicate that the final model fits the data well. 


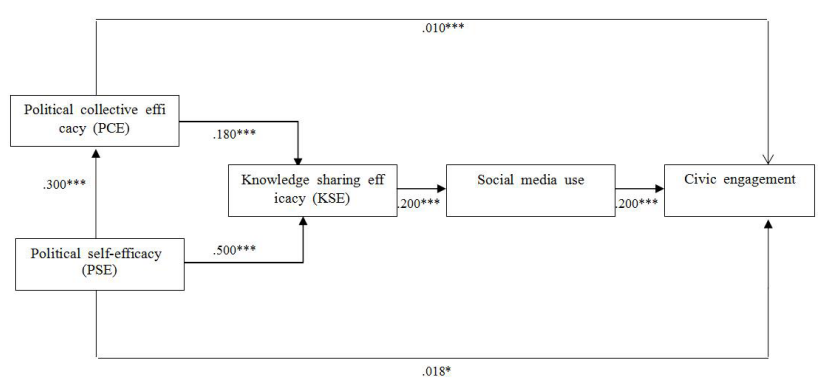

Figure 2. The results of hypothesis testing and Suggested Final model

Note:

$* * * p<.001$

\section{Discussion}

The major goal of this study was to delineate a research framework with which we could identify how efficacy beliefs (e.g., PSE, PCE, and KSE) and social media use have effects on civic engagement. Overall, the findings show that (1) PSE, PCE, and KSE have positive relationships with one another, (2) social media use, PSE, and PCE have positive effects on civic engagement, and (3) both the paths from PSE and PCE to social media use are fully mediated by KSE.

\subsection{Inter-relations Among Three Efficacy Beliefs}

In political and civic matters, PCE and PSE are specific efficacy beliefs. These beliefs are developed to test the efficacy beliefs in a specific context or tasks such as civic engagement. As Bandura (1997) asserts, efficacy is a specific belief that must be tested for specific situations. ${ }^{[11]}$ In the digital age where social media use is normalized and normative for various social movements, it is imperative to develop and test a context specific efficacy belief. Likewise, KSE is a specific efficacy belief that tests one's perceived capacity in promoting collective causes by sharing knowledge and information in an open environment.

Consistent with the findings of recent studies ${ }^{[8,9]}$, we found positive relationships among PSE, PCE, and KSE. Given that the three efficacy beliefs share similar founding belief that one has the capability to accomplish certain tasks, this finding is not surprising. However, it is worth noting that PSE $(\beta=.503, \mathrm{p}<.001)$ had a larger effect while PCE $(\beta=.175, \mathrm{p}<.001)$ had a smaller effect on KSE.

A large effect size of PSE on KSE can be explained considering that skills, efforts, and endurance are required in performing a task, that is, an individual with higher PSE is confident about his or her knowledge in terms of its accuracy, completeness, depth, and relevancy.

The smaller effect of PCE on KSE is because the basis of PCE is not an assessment of an individual's capability but a group's capability. Even though a person is ensured about the group's ability to make positive changes for politics, an individual can be discouraged from sharing information in concerns of criticism or negative outcomes of information sharing. Therefore, an individual should overcome the pressure based on one's own knowledge sharing efficacy. Social media interactions expand the boundary of one's personal networks, creating instantaneous exposure to the audience of different views, opinions, and sentiments about an issue. Even though PCE increases KSE in the hope of benefiting the group and promoting the causes, PCE alone is insufficient to withstand and manage emotional stress from social media exchanges. Therefore, PCE only explains a small portion at KSE.

\subsection{The Role of KSE in Social Media Use}

we argue that confidence about the values and utility of one's knowledge helps one overcome the fear of receiving criticism and creating negative impressions, and encourages one to share knowledge on social media. The negative experiences and feelings that people often receive from participating in online discussions and interactions have been reported as a major deterrent of online participation. A recent study reveals that debate and discussion on social media have created anxiety and frustration due to an aggressive and disrespectful tone of political discussions on social media. ${ }^{[57]}$ Thus, a strong level of KSE where people believe they have good enough knowledge to defeat the naysayers against civic movement is a prerequisite for social media interactions.

Moreover, the study found the full mediation of KSE on the relationships between PSE and social media, and PCE and social media. This means, PSE and PCE increase $\mathrm{KSE}$, which, in turn, increases social media use for civic engagement. Based on our post-hoc analysis, we arrive at the final model which excludes insignificant paths between PSE, PCE and social media use. Further, we found that the addition of the path between KSE and civic engagement significantly enhances the final model. So, these findings highlight a mediating role of KSE in yielding both social media use and civic engagement, eliminating the direct effect of PSE and PCE on social media use.

Social media environment can be hostile and aggressive. Without the conviction that one's knowledge is worth and beneficial for the collective processes (Kalman et al., 2002; Lin, 2007), a person may not be motivated to use social media for civic engagement. ${ }^{[15,16]}$ Adding 
KSE to the research model significantly contributes to the understanding of the role of social media and civic engagement.

\subsection{Social Media Use and Civic Engagement}

Consistent with past studies, ${ }^{[38,39,40,44,45,46]}$ our study also found social media, PSE, and PCE have positive, but varying effects on civic engagement which highlight the mediating role of social media in inducing civic engagement. Past studies have found a positive significant effect of PSE and PCE on civic engagement. Efficacy beliefs about one's own capability (PSE) and the group's capability (PCE) to make positive changes are strong determinants in inducing civic engagement among the public.

Interestingly, however, the result of this study found weak effects of PSE $(\beta=.079, p<.05)$ and PCE $(\beta=$ $.078, \mathrm{p}<0.001)$ and a strong effect of social media use $(\beta=.281, p<.001)$ on civic engagement. This implies that in the digital age, civic and social movements are extensively triggered and prompted by social media use, mediating the paths from PSE and PCE, to civic engagement, respectively. Our post-hoc analysis confirms this interpretation. When social media use was removed on the paths between PSE and PCE and civic engagement from the model, the effects of PSE and PCE were increased significantly (for PSE, $\beta=.239, p<0.001$ and for PCE, $\beta=.141, p<0.001)$. These findings indicate that mediating effect of social media use to connect efficacy and civic engagement is strong enough to offset the direct effects of those efficacies on civic engagement.

We also have noted the importance of social media use in generating civic engagement as a major driver. The current civic engagement is characterized by excessive use of social media. Social media have become the most useful and critical tool and space to read and share news about social issues, to educate people about their rights and alternative actions, to connect people and create alliances among various groups, and to mobilize and organize collective actions online and offline. Given that our measure of civic engagement encompasses various online and offline actions, the result of this study confirms that social media undoubtedly has the potential to support collective actions of all sorts.

Our study has a few theoretical implications. To the best of our knowledge, this research is the first to demonstrate that KSE is an important predictor of social media use in civic engagement. No studies have explored the specific efficacy belief that reflects the unique characteristics of social media use and consequential effects such characteristics render. We believe civic engagement research can be benefited by incorporating KSE concepts to reflect the changing nature of civic engagement in a social media context. Our study also contributes to the civic engagement research by elaboration on the mechanism through which the three efficacy beliefs, namely PSE, PCE, and KSE, and social media use facilitate civic engagement. The findings show that in the digital environment, PSE and PCE, through the mediation of KSE, influence social media use, which, in turn, increases civic engagement.

The study moves beyond examining political engagement as a major form of civic engagement. We note that major drivers in yielding civic engagement might differ from political engagement. The latter tends to be motivated by political leaning and ideology, but the former is based rather on altruism and ethical consumerism, including a wider range of social behaviors such as charitable donations, ethical consumerism to punish companies perceived as immoral, and so on.

Further, we propose and validate a comprehensive measurement of civic engagement across online and offline platforms. As noted, civic engagement largely is prompted by various types of online campaigns and, in turn, such engagement often leads to offline movement and participation creating social change. Accordingly, we expect our exhaustive measurement items of civic engagement encompassing offline and online activities would contribute to the further examination of civic engagement.

Taken together, the findings suggest that the technological characteristics of social media have significantly changed the nature of civic engagement, making it more interactive, complex, and dynamic, which tests one's confidence about knowledge sharing capability. We believe that our research approach focusing on the different types of efficacy belief can give insights to civic engagement in a new media landscape.

\section{Appendix}

\section{Political self-efficacy (9 items)}

How much would you say you agree with each of the following statements? Please select the answer that best represents your interest level in politics.

I consider myself to be well qualified to participate in politics.

(1) Generally speaking, I feel that I have a pretty good understanding of the important political issues facing our country.

(2) I feel that I can do as good a job in public office as most other people. 
(3) I think that I am better informed about politics and the government than most people.

(4) Sometimes politics and government seem so complicated that a person like me can't really understand what's going on.

(5) People like me don't have any say about what the government does.

(6) I don't think public officials care much about what people like me think.

(7) I believe having elections makes the government pay attention to what the people think.

(8) I think the government pays attention to what people think when it decides what to do.

\section{Political collective efficacy (11 items)}

How much would you say you agree with each of the following statements? Choose an option that best represents your answer.

(1) A dramatic change could occur in this country if people banded together and demanded change.

(2) If enough people banded together and demanded change, politicians would take the steps to enact change.

(3) Organized groups of citizens can have much impact on the political policies in this country.

(4) Politicians would respond to the needs of citizens if enough people demanded change.

(5) Politicians would listen to homeless and poor people if we pressured them to.

(6) As people in this country, we can all band together in order to achieve political goals.

(7) We are definitely able to accomplish something positive since we are a competent group of people.

(8) As a people, we can cooperatively develop and carry out programs to benefit us all, even when difficulties arise.

(9) $\mathrm{We}$, as one people, are able to struggle together in order to achieve political goals.

(10) Since we are all competent in engaging in collective action, we can forward our political demands successfully.

(11) We can work together to promote important political goals even if we face difficulties.

\section{Knowledge sharing efficacy (5 items)}

How much would you say you agree with each of the following statements? Choose an option that best represents your answer.

(1) I am confident in my political knowledge that is valuable to others (in our society, in my social networks, in my personal network).
(2) I have the expertise required to provide valuable knowledge for others (in our society, in my social networks, in my personal network).

(3) It does not really make any difference as to whether or not I share my knowledge with others (in our society, in my social networks, in my personal network).

(4) I believe that my knowledge will be appreciated by others.

(5) I am confident that my knowledge is useful.

\section{Civic participation (15 items)}

(1) I have attended a meeting of discussion or dialogue organized by the residents' committees, community centres, or the government.

(2) I have participated in events for a cause or a charity (e.g., Hair for Hope, Yellow Ribbon Prison Run, etc.)

(3) I have worn or put a badge, a sticker, or a ribbon on me or on my possessions such as phones, notebooks, bags, bicycles, or cars to express my support for a cause or a charity.

(4) I have joined or volunteered for welfare/charitable organizations or other nongovernmental organizations.

(5) I have donated money to welfare/charitable organizations or other nongovernmental organizations.

(6) I have deliberately purchased certain products or services for political/ethical/environmental reasons.

(7) I have boycotted certain products or services for political /ethical/environmental reasons.

(8) I have "liked" the contents about political and social issues on social media sites such as Facebook or Twitter.

(9) I have shared political and social issues with other people on social media such as Facebook or Twitter.

(10) I have written about political or social issues on social media such as Facebook or Twitter.

(11) I have written to the newspapers, the government, or a member of Parliament.

(12) I have taken part in the discussion about politics or social issues on websites such as online forums or blogs.

(13) I have taken part in the discussion about politics or social issues on social media such as Facebook or Twitter.

(14) I have signed an online petition about a local, national, or international issue.

(15) I have worked together with others in online groups to try to deal with a local issue or a problem.

\section{Social Media Use (2 items)}

The next set of questions asks about your use of media for searching for news on politics, public issues, and government policy. Please provide your answer in fiveminute intervals (from 5 to $100+$ ). Usually, on a typical 
day, how many minutes a day do you spend on reading or listening to the following?

(1) Facebook

(2) Twitter

\section{References}

[1] Isaac, M. Inside Uber's aggressive, unrestrained workplace culture. The New York Times, 2017. Retrieved from:

https://www.nytimes.com/2017/02/22/technology/ uberworkplace-culture.

[2] Marinova, P. 2017. Retrieved from https://fortune. com/2017/02/21/delete-uber-twitter/

[3] Morse, J. 2017. Retrieved from https://mashable. com/2017/02/22/uber-message-when-delete-accountsusan-fowler-blog-post/

[4] Netzley, M. A., Gidantrai B.D., Wong, D. Y. M., Tan, W. U.L., Hee, Y. J. Starbucks in Forbidden City. Singapore: Singapore Management University, 2011. Retrieved from:

http://ink.library.smu.edu.sg/cases_coll_all/7/

[5] Mackey, R. Indian Rapper Calls Out Unilever to a Nicki Minaj Beat, 2015. Retrieved April 29, 2017, from https://www.nytimes.com/2015/08/01/world/asia/indian-rapper-calls-out-unilever-to-a-nicki-minaj-beat

[6] Gil de Zúñiga, H., Molyneux, L., Zheng, P. Social media, political expression, and political participation: Panel analysis of lagged and concurrent relationships. Journal of Communication, 2014, 64(4): 612-634.

[7] Eveland Jr, W. P. and Scheufele, D. A. Connecting news media use with gaps in knowledge and participation. Political Communication, 2000, 17(3): 215-237.

[8] Shen, F., Wang, N., Guo, Z., Guo, L. Online network size, efficacy, and opinion expression: Assessing the impacts of Internet use in China. International Journal of Public Opinion Research, 2009, 21(4): 451-476.

[9] Easton, D., Dennis, J. The child's acquisition of regime norms: political efficacy", The American Political Science Review, 1967, 61: 25-38.

[10] Verba, S., Schlozman, K. L., Brady, H. E. Voice and equality: Civic volunteerism in American politics. Cambridge, MA: Harvard University Press, 1995.

[11] Bandura, A. Self-Efficacy: The Exercise of Control. New York: Freeman, 1997.

[12] Harris, Joseph P. The Voter Decides. By Angus Campbell, Gerald Gurin and Warren E. Miller. (Evanston, Ill.: Row, Peterson and Co.1954. Pp. xiii, 242. \$4.75), American Political Science Review, 1955, 49(1): 225-228.

[13] https://www.theatlantic.com/photo/2011/09/occupy-wall-street/100159/

[14] http://www.alsa.org/fight-als/ice-bucket-challenge. html

[15] Kalman, M. E., Monge, P., Fulk, J., Heino, R. Motivations to resolve communication dilemmas in database-mediated collaboration. Communication Research, 2002, 29(2): 125-154.

[16] Lin, H. F. Effects of extrinsic and intrinsic motivation on employee knowledge sharing intentions", Journal of Information Science, 2007, 33(2): 135-149.

[17] Gil de Zúñiga, H., Copeland, L., Bimber, B. Political consumerism: Civic engagement and the social media connection. New Media \& Society, 2013, 16(3): 488-506.

[18] Kwak, H., Lee, C., Park, H., Moon, S. What is Twitter, a social network or a news media?. In Proceedings of the 19th International conference on World Wide Web, ACM, 2010: 591-600.

[19] Fenton, N., Barassi, V. Alternative media and social networking sites: The politics of individuation and political participation. The Communication Review, 2011, 14(3): 179-196.

[20] Hampton KN, Lee CJ, Her EJ. How new media affords network diversity: Direct and mediated access to social capital through participation in local social settings. New Media \& Society, 2011, 13(7): 103149.

[21] Pingree, R. J. How messages affect their senders: A more general model of message effects and implications for deliberation. Communication Theory, 2007, 17(4): 439-461.

[22] Ellison, N. B., Steinfield, C., Lampe, C. The benefits of Facebook "friends": Social capital and college students use of online social network sites. Journal of Computer-Mediated Communication, 2007, 12(4): 1143-1168.

[23] Park, N., Kee, K. F., Valenzuela, S. Being immersed in social networking environment: Facebook groups, uses and gratifications, and social outcomes", CyberPsychology \& Behavior, 2009, 12(6): 729-733.

[24] Valenzuela, S., Park, N., Kee, K. F. Is there social capital in a social network site? Facebook use and college students' life satisfaction, trust, and participation. Journal of Computer-Mediated Communication, 2009, 14: 875-901.

[25] Pearce, K. E., Kendzior, S. Networked authoritarianism and social media in Azerbaijan. Journal of Communication, 2012, 62: 283-298.

[26] Valenzuela, S., Arriagada, A., Scherman, A. The social media basis of youth protest behavior: The case of Chile. Journal of Communication, 2012, 62: 299314.

[27] Valenzuela, S. Unpacking the use of social media for protest behavior: The roles of information, opinion 
expression, and activism. American Behavioral Scientist, 2013, 57(7): 920-942,

[28] Velasquez, A., LaRose, R. Youth collective activism through social media: The role of collective efficacy. New Media \& Society, 2015, 17(6): 899-918.

[29] Bimber, B., Coperland, L. Digital media and traditional political participation over time in the U.S.. Journal of Information Technology \& Politics, 2013, 9(4): 352-369.

[30] Kim, Y., Hsu, S.-H., Gil de Zúñiga, H. Influence of social media use on discussion network heterogeneity and civic engagement: the moderating role of personality traits. Journal of Communication, 2013, 63: 498-516.

[31] Gil de Zúñiga, H., Jung, N., Valenzuela, S. Social media use for news and individuals' social capital, civic engagement and political participation. Journal of Computer-Mediated Communication, 2012, 17: 319-336.

[32] Shirky, C. Here Comes Everybody: The power of organizing without organizations. New York: Penguin, 2008 .

[33] Holden, G. The relationship of self-efficacy appraisal to subsequent health-related outcomes: A meta-analysis. Social Work in Health Care, 1991, 16: 53-93.

[34] Stajkovic, A. D., Luthans, F. Self-efficacy and work-related performance: A meta-analysis. Psychological Bulletin, 1998, 124(2): 240-261.

[35] Brunsting, S., Postmes, T. Social movement participation in the digital age: Predicting offline and online collective action. Small Group Research, 2002, 33(5): 525-554.

[36] Niemi, R. G., Craig, S. C., Mattei, F. Measuring internal political efficacy in the 1988 National Election Study. American Political Science Review, 1991, 85(04): 1407-1413.

[37] Delli Carpini MX. Gen. com: Youth. Civic engagement, and the new information environment. Political communication. 2000, 17(4): 341-349.

[38] Hoffman, L. H., Thomson, T. L. The effect of television viewing on adolescents' civic participation: Political efficacy as a mediating mechanism. Journal of Broadcasting \& Electronic Media, 2009, 53(1): 3-21.

[39] Hope, E. C. Preparing to participate: The role of youth social responsibility and political efficacy on civic engagement for black early adolescents. Child Indicators Research, 2016, 9(3): 609-630.

[40] Kahne, J., Westheimer, J. The limits of political efficacy: Educating citizens for a democratic society. Political Science and Politics, 2006, 39(2): 289-296.

[41] Mullen, B., Copper, C. The relation between group cohesiveness and performance: Integration. Psycho- logical Bulletin, 1994, 115 (2): 210-227.

[42] Sampson RJ, Raudenbush SW, Earls F. Neighborhoods and violent crime: A multilevel study of collective efficacy. Science, 1997, 15, 277(5328): 91824

[43] Yeich, S., Levine, R. Political efficacy: Enhancing the construct and its relationship to mobilization of people. Journal of Community Psychology, 1994, 22(3): 259-271.

[44] Browning, C. R. The span of collective efficacy: Extending social disorganization theory to partner violence. Journal of Marriage and Family, 2002, 64(4): 833-850.

[45] Skrabski, Á., Kopp, M., Kawachi, I. Social capital in a changing society: cross sectional associations with middle aged female and male mortality rates. Journal of Epidemiology and Community Health, 2003, 57(2): 114-119.

[46] Burdette, H. L., Wadden, T. A., Whitaker, R. C. Neighborhood safety, collective efficacy, and obesity in women with young children. Obesity, 2006, 14(3): 518-525.

[47] Zimmerman, B. J., Bandura, A., Martinez-Pons, M. Self-motivation for academic attainment: The role of self-efficacy beliefs and personal goal setting. American Educational Research Journal, 1992, 29(3): 663676.

[48] Aslam, S. Facebook by the Numbers: Stats, Demographics \& Fun Facts. Omnicore, 2018. Retrieved from:

http://www.omnicoreagency.com/facebook-statistics/

[49] Kenski, K., Stroud, N. J.. Connections between Internet use and political efficacy, knowledge, and participation. Journal of Broadcasting \& Electronic Media, 2006, 50(2): 173-192.

[50] Hayes, R. A. New media, new politics: Political learning efficacy and the examination of uses of social network sites for political engagement. Available from ABI/INFORM Collection; ProQuest Dissertations \& Theses Global. (304952463), 2009. Retrieved from:

http://libproxy1.nus.edu.sg/login?url=http:// search.proquest.com.libproxy1.nus.edu.sg/ docview/304952463? accountid $=13876$

[51] Tamjidyamcholo, A., Baba, M. S. B., Tamjid, H., Gholipour, R. Information security-Professional perceptions of knowledge-sharing intention under self-efficacy, trust, reciprocity, and shared-language. Computers \& Education, 2013, 68: 223-232.

[52] Van Acker, F., Vermeulen, M., Kreijns, K., Lutgerink, J., van Buuren, $\mathrm{H}$. The role of knowledge sharing self-efficacy in sharing open educational resourc- 
es. Computers in Human Behavior, 2014, 39: 136144.

[53] Cho, H., Chen, M., Chung, S. Testing an integrative theoretical model of knowledge-sharing behavior in the context of Wikipedia. Journal of Association for Information Science and Technology, 2010, 61(6): 1198-1212.

[54] Ardichvili, A., Maurer, M., Li, W., Wentling, T., Stuedemann, R. Cultural influences on knowledge sharing through online communities of practice. Journal of Knowledge Management, 2006, 10(1): 94-107.

[55] Usoro A, Sharratt MW, Tsui E, Shekhar S. Trust as an antecedent to knowledge sharing in virtual communities of practice. Knowledge Management Research \&
Practice. 2007, 5(3): 199-212.

[56] https://www.singstat.gov.sg/-/media/files/publications/population/population2016.pdf

[57] Infocomm Development Authority of Singapore. Annual Survey on Infocomm Usage in Households and By Individuals for 2014, 2015. Retrieved from https://www.imda.gov.sg/-/media/Imda/Files/Inner/ Infocomm-Landscape/Facts-and-Figures/SurveyReports/2014/2014-HH-public-report-final.pdf?la=en.

[58] Duggan, M., and Smith, A. The Political Environment on Social Media. 2016. Retrieved April 01, 2017, from

http://www.pewinternet.org/2016/10/25/the-political-environment-on-social-media/ 


\section{University Library}

\section{- M M N E R VA A gateway to Melbourne's research publications}

Minerva Access is the Institutional Repository of The University of Melbourne

Author/s:

Chung, S;Shim, K

Title:

Understanding Antecedents of Civic Engagement in the Age of Social Media: From the Perspective of Efficacy Beliefs

Date:

2020-08-12

Citation:

Chung, S. \& Shim, K. (2020). Understanding Antecedents of Civic Engagement in the Age of Social Media: From the Perspective of Efficacy Beliefs. Journal of Psychological Research, 2 (3), https://doi.org/10.30564/jpr.v2i3.1839.

Persistent Link:

http://hdl.handle.net/11343/263722

License:

CC BY 